\title{
Yesterday's tomorrow, today: Medical quality management
}

\author{
ABR THOMSON, MD, PHD, FRCPC, FACP, FRS, FACG
}

I F WE ARE TO IMPROVE THE HIGH QUALITY OF CARE further, which we already presume that we provide for our patients, we first need to develop a nurturing environment so that our skills can be used at every stage of the patient care process and so that improvements in quality can be done against the background of acceptance and approval. Yesterday's future is here today, and already we need to be consid. ering a new tomorrow. You may have heard ad nauseam the need to develop a greater 'high-tech' approach for survival in the 'New World order', but perhaps we should join futurist John Naisbitt and add a human dimension to this technological bureaucratic approach and consider redirection of 'quality' as 'high touch'. But why should we consider it necessary to develop a medical quality improvement (MQI) program, since we each presume that we are all already doing our best? A hospital or a medical practice without an MQI program is like a school without examinations or the Montreal Canadiens playing the Edmonton Oilers without keeping score! As Robert Burns wrote, "look abroad through Nature's range, Nature's mighty law is change". We are part of that change, or at least we need to consider that perhaps we should be.

Easily two-thirds of the Canadian gastrointestinal community is now comprised of 'baby boomers', born between 1946 and 1964. For some of our older clinicians who now feel the cruelty and uncertainty of mandatory age 65 retirement, the baby boomers' attitudes towards their practice of gastroenterology may at times seem - perhaps wrongly - to be filled with an attitude of stressing issues of quality of life and pampered lifestyle. Some have suggested that youth "spurn

Nutrition and Metabolism Research Group, Division of Gastroenterology, Department of Medicine, University of Alberta, Edmonton, Alberta

Correspondence and reprints: Dr ABR Thomson, 519 Robert Newton Research Building, University of Alberta, Edmonton, Alberta T6G 2C2. Telephone (403) 492-6490, Fax (403) 492-7964

Received for publication April 29, 1993. Accepted July 8, 1993 discipline for permissiveness, reject authority figures, insist on immediate gratification, and seek participation in decision making " (1). While not all of us would necessarily agree with this assessment, it is clear as we look at our very youngest colleagues that their attitudes may differ from those upon whose shoulders we all now stand. So there is a need for MQI and quality assurance (QA) - the time is right and the personal conditions of many of us are also right.

\section{MQI AND QA}

I do not wish to focus upon the strengths and weaknesses of these perceived new attitudes, but rather to stress that any process for change, be it among physicians, nurses, teachers or politicians, must take into account the very fibre and fabric of the attitudes, beliefs and concerns of all of us. We are in the new 'information age'. We have moved the labour market forces of the blue collar worker to white collar, to what we might now consider for ourselves, the 'gold collar' workforce in which we are experts in our field. What used to happen was as one advanced through promotions and awards, salaries increased with academic rank and one moved into the management sphere. Those of us practising, be it in the community or in the hospital, nonetheless work within the framework of a medical hierarchy in which we gold collar workers involve ourselves in continuing medical education and may become leaders in our field, but where is the room for 'advancement'? Moving into a management role in middle or advancing years no longer holds the prospect of 'seniority'. Our own sense of self-worth comes more from that internal force of acceptance of who we are and what we do, and less from the holding of a title of respect from maturity and experience. With government and hospital bureaucracy ever challenging us to prove that what we do - our best - is in fact the best we can be, the focus increasingly is on issues of quality.

What do we do when doing our best is not 'best' enough? We need to respond to the future, taking a great deal on faith, for "life can only be understood backwards; but it must be lived 
forwards" (1). The challenges for the future, and the challenges for MQI and QA include the interwoven issues of quality, service, innovation and productivity (1). "It is a funny thing about life, if you refuse to accept anything but the very best you very often get it" (William Somerset Maugham). But just what is 'quality'? The American Society for Quality Control defines quality as "a systematic approach to the search for excellence". Fischer and Mandolese (2) suggest that quality "is the degree of timely adherence to generally recognized contemporary standards of quality and care and the achievement of anticipated outcomes for a particular service, procedure, diagnosis or clinical problem, and appropriateness is the extent to which a particular procedure, treatment, test or service is efficacious, clearly indicated, not excessive, adequate in quantity and provided in the setting (in-patient, out-patient or other) best suited to meet the patient's needs". Simply put, are we doing the right things? Are we doing these things right? Perhaps the time has come for us to use creative energies to institute MQI programs in our practices. Some of the perspectives of quality control have been in place for years in the automotive, engineering and pharmaceutical industries. Along this medical journey we may create original applications, processes, products and services which will be of benefit to our profession and to our patients. This is a personal challenge, but it is also a further challenge for our professional organizations, which will need to begin to act - soon - now.

The conditions for innovation need to be recognized for all of this to happen. The implementation of an MQI program needs to be done in a nurturing environment, perhaps encouraged by administration, but always accepted by physicians and nurses as part of the way in which we can do even better than we are doing already. Quality improvement is tomorrow's child today. To accept these programs, we need to be committed, and our administration needs to be prepared for the difficulties which this will give rise to, as this is initially a process of defensive self-examination. But, like all forms of innovation, the environment must be supportive for the creativity in the hearts and minds and souls of each of us to take home to blossom. "Innovation is like a rainbow: it doesn't happen because you want it, it happens because the conditions are right to make it happen" (1). We require a state of mind to create new ideas, whether it be in the setting of a research institute or university facility, or whether it is in the context of a community hospital in which we are being innovative in applying new technology, outcome analyses and cost-saving measures. Our bureaucracy needs to create "an atmosphere that encourages innovation and then [gives] power to the people with the skills to achieve the desired result ... [this] is the key to successful innovation" (1).

Spurred by the dedication to improve quality linked to the benefits of innovation and improved medical service, productivity and cost-savings will follow. Management may use their knowledge and skill with financial, production, service and administration systems, but these technologies require the respect for and acceptance of health care workers. The system must not be allowed to destroy the innovative process, and we as physicians may help in the leadership of the innovative process. It is the health care workers - ourselves - who know firsthand what our patients (how I dislike the word 'client' or 'customer' in this context) need and what our profession requires to maintain its independence and dedication. But we too must recognize that the new technologies include that of the 'physician manager' who is prepared to discuss budgetary considerations with management in a team partnership in which there is one winner, the patient. The 'patient' may soon be ourselves, our family or our extended community. We struggle for balance, and this is an ongoing and dynamic process.

McNeil and Clemmer, in their book The VIP Strategy (1), outline their creation of the 'vision, integrated performance leadership' blueprint which evolved into the 'VIP strategy'. "The VIP strategy outlines the direct relationship between what the members of an organization contribute to it (vision/values) and what the organization produces (performance: quality, innovation and service). The four basic skills of leadership become the mechanisms or catalysts that release the energy contained in vision, values, environment and behaviour". In their dynamic book, which is clearly written and an 'easy read', they outline the need for vision, and the energy to inspire and motivate us to work with our hearts, heads and hands to improve the quality of our performance and our organizations. Visions are pro-active, visions become reality, for "where there is no vision, the people perish" (Prov. 29:18). The spiritual and metaphysical elements allow us to see the future as we would wish it to be, and this vision of excellence within the Canadian framework of universal health care will be the magnetic force that can draw our profession together, and will provide the individual inspiration and direction which our professional organizations do not necessarily afford us. Perhaps management belongs on the bottom, rather than on the top, of our hospital power structure - at the bottom of the pyramid in a supporting role, with our patients at the top, and we physicians in the intermediate supportive and facilitating role as the patient advocates. In this role we make a promise of $Q A$.

QA is a promise of performance, that I give, "as the provider of a service, QA is ... the act of assuring, the evidence, guarantee or earnest of what I am promising, and the state of certainty which should be shared by the provider and the client" (3). QA is a message, a communication, a measurement. Crosby $(4,5)$ defined quality as "conformance with requirements". This is the discipline of continuously and consistently measuring behaviour against goals. The result of QA "is patient care that is more effective, reliable, sensitive and holistic" (3). Avedis Donabedian broadly defines QA as including "all that we do to safeguard and promote the quality of health care" (6). Three approaches were used to assess the quality of care: structure, process and outcome. QA is a management system by means of which we assure ourselves and others of the quality of work for which we have responsibility. QA is chiefly for our patients, who need our expertise and caring, not sometimes but always. Care must be expert, reliable and sympathetic.

QA is defined by the Canadian Council on Hospital Ac- 
creditation (CCHA), the national agency that accredits health care facilities of all descriptions across Canada, as a five-stage process comprising:

- establishment of functional goals;

- implementation of procedures to achieve those goals;

- regular assessment of performance relative to the goals;

- proposal of solutions to close the gap between performance and goal; and

- documentation and reporting of this assessment activity.

QA can be a user-friendly program in which groups of physicians working in a specialty area (such as a Division of Gastroenterology) will define certain standards of practice, review these standards to determine how they are doing and then modify their future practice behaviour to come closer to the goals and standards which they have set for themselves. This is action-oriented and gives results via shorter length of hospital stay, reducing unnecessary procedures and identifying areas in which improvement is appropriate.

Beyond the problem-oriented QA model is the focus on outcome measures of care to continuous improved quality. To achieve this continuous quality improvement, the emphasis of monitoring and evaluation should "progressively shift from individual 'outlier' identification to ongoing assessment of the composite performance of key functions" (7). This MQI, endoscopy quality improvement, total quality management or continuous quality improvement focuses on a continuous effort to improve the system, a long term horizontal process/philosophy that involves all levels of the organization. Thus, quality improvement goes beyond $\mathrm{QA}$ as a standard for achieving quality. The movement to quality improvement is the shift from managing to leading, a pro-active team approach in which administrative authority is replaced by participation and improvement.

For further reading, I would recommend The Quest for Quality and Productivity in Health Services by Sahney and Warden (8), TQM (Total Quality Management) and Clinical Medicine by BC James (9), and Blazing the Trail of Quality by DM Berwick (10).

\section{BIBLIOGRAPHY}

1. McNeil A, Clemmer J. The VIP Strategy: Leadership skills for exceptional performance. Toronto: Key Porter Books, 1989.

2. Fischer JD, Mandolese J. Objective occurrence screening program - a tool for outcomes measurement. Can J Qual Health Care 1992;9:16-8.

3. Wilson CRM. Hospital-wide quality assurance: Models for implementation and development. Toronto: WB Saunders, 1987.

4. Crosby P. Quality is free: The art of making quality certain. New York: New American Library, 1979.

5. Crosby P. Quality without tears: The art of hassle-free management. New York: McGraw-Hill, 1984.

6. Donabedian A. The process of quality assurance. Bernard Snell Lecture, Faculty of Medicine, University of Alberta, Edmonton, 1992.

7. O'Leary D. CQI - A step beyond QA. Quality Review Bulletin 1991; January: 4-5.

8. Sahney VK, Warden GL. The process of total quality management in health care. Frontiers of Health Services Management. 1991;7:2-40.

9. James BC. TQM and Clinical Medicine. Frontiers of Health Services Management. 1991;7:42-6.

10. Berwick DM. Blazing the trail of quality: The HFHS quality management process. Frontiers of Health Services Management 1991;7:47-50. 


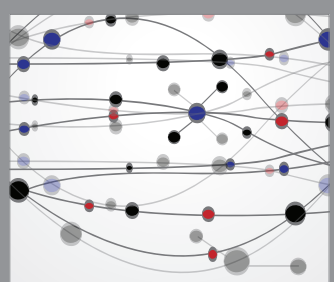

The Scientific World Journal
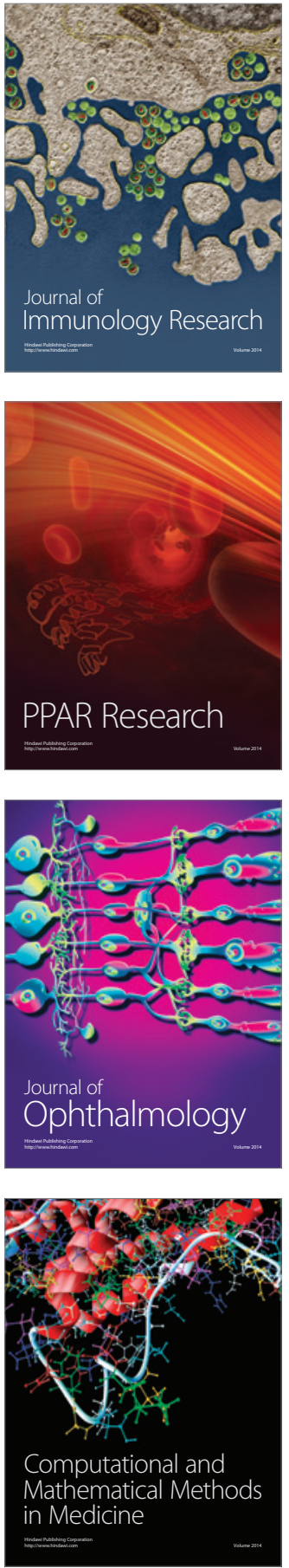

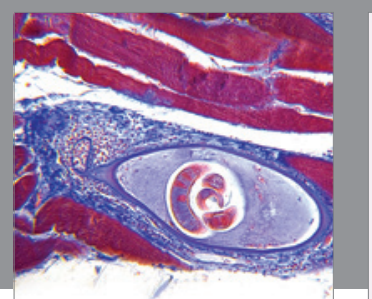

Gastroenterology Research and Practice

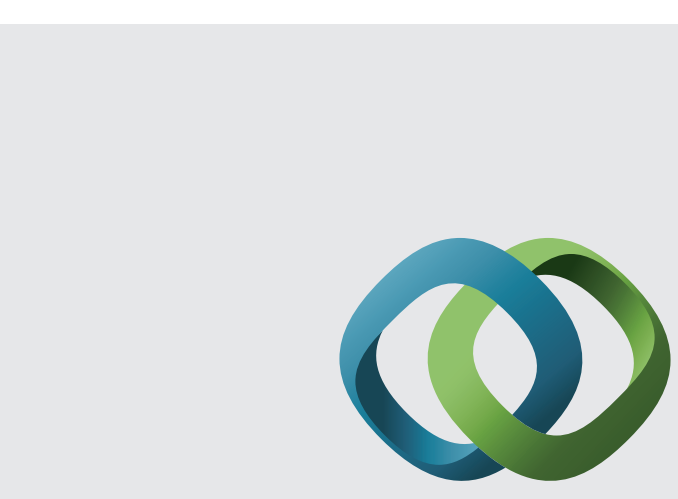

\section{Hindawi}

Submit your manuscripts at

http://www.hindawi.com
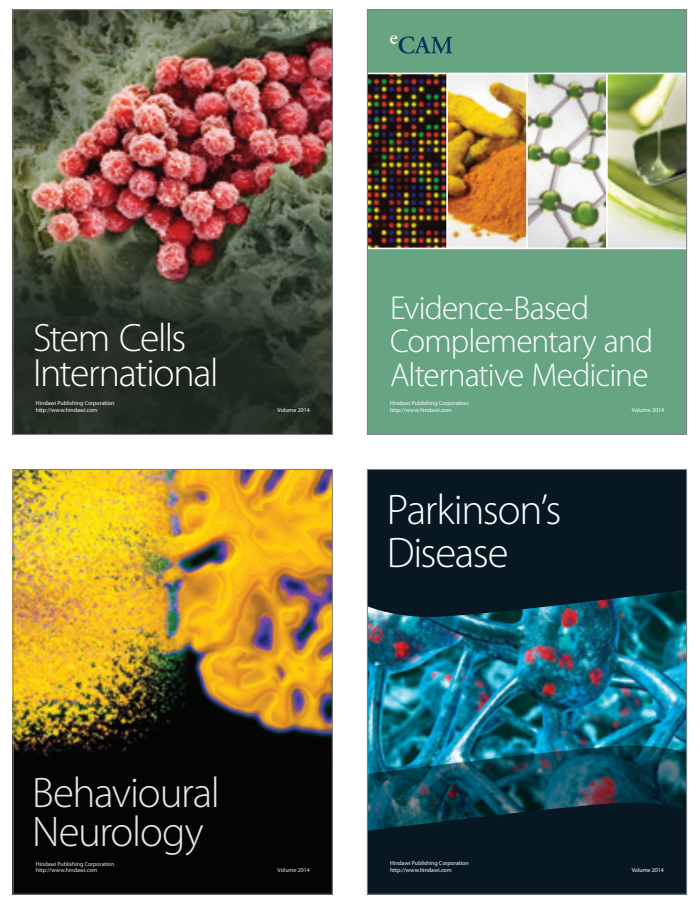
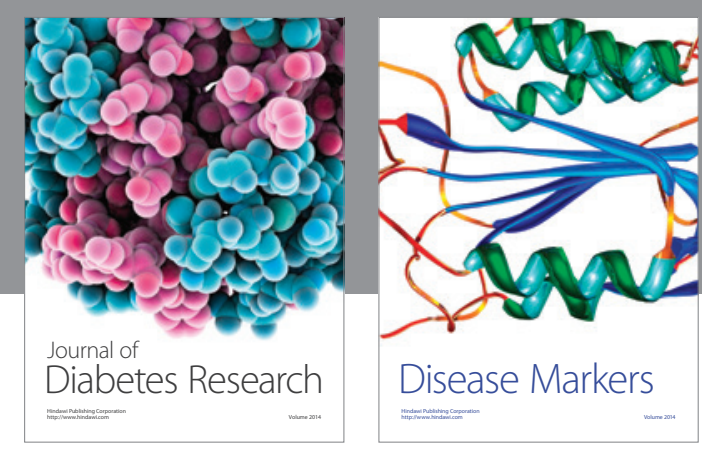

Disease Markers
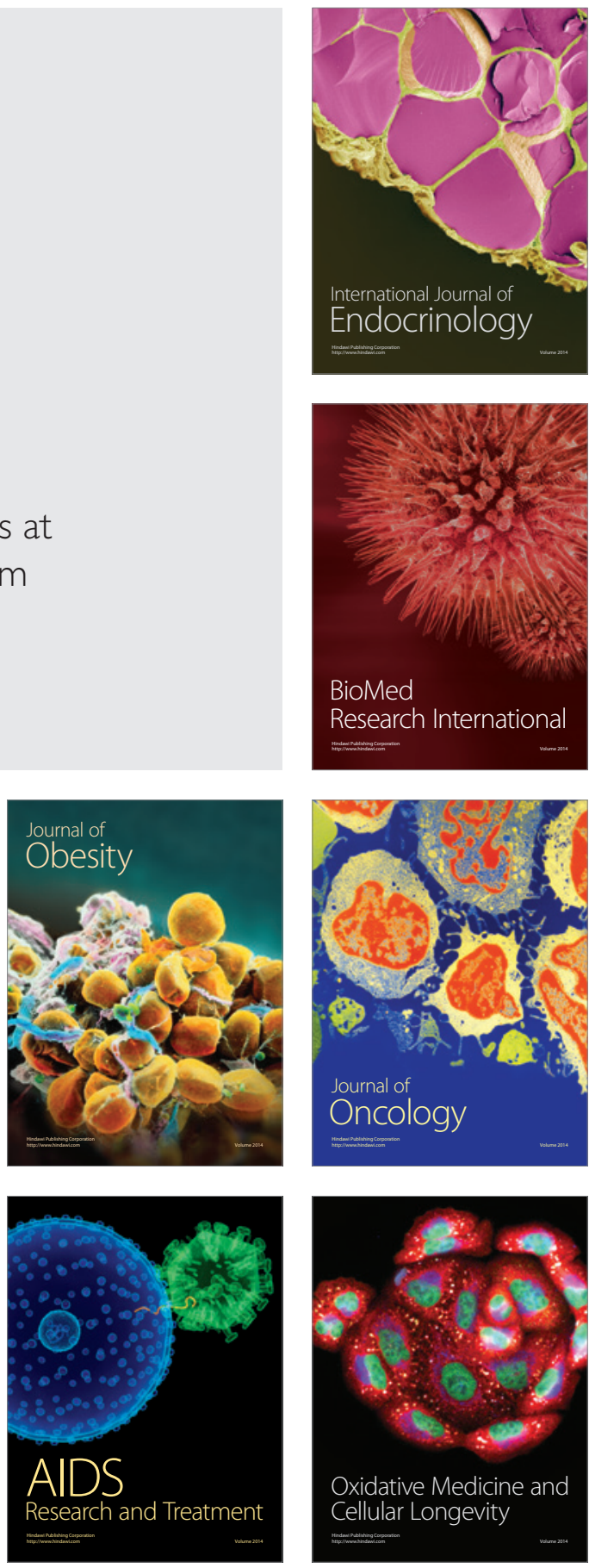